Revista Iberoamericana. Vol. LXII, Núms. 176-177, Julio-Diciembre 1996; 719-729

\title{
LOS DERECHOS HUMANOS, HERMENÉUTICA PARA LA CRÍTICA LITERARIA Y LOS ESTUDIOS CULTURALES LATINOAMERICANISTAS: INFORME DE UNA EXPERIENCIA
}

\author{
POR \\ HERNÁN VIDAL \\ University of Minnesota
}

Presento aquí un informe de esfuerzos por establecer una hermenéutica cultural basada en la defensa de los derechos humanos definidos tanto por la Declaración Universal de Derechos Humanos de las Naciones Unidas (1948) y sus Pactos Complementarios (1966) como por los Convenios de Ginebra (1948) y sus Protocolos Adicionales (1977), que rigen durante conflictos armados. El interés que pueda tener este informe radica en dos tipos de implicaciones. Por una parte están los efectos burocrático-administrativos sobre los departamentos universitarios de lengua y literatura. Más allá de esto, sin embargo, deseo llamar la atención sobre una manera de dar mayor trascendencia humanística a los estudios literarios y culturales en un período en que han perdido el prestigio que tuvieran hace décadas.

Estoy consciente de que hoy en día la crisis de los discursos científicos de redención humana hace dudoso todo intento de totalización de la experiencia histórica de la especie. La actual discusión del tema de la postmodernidad sirve como testimonio de esto. No obstante, los debates humanísticos sobre la postmodernidad se llevan a cabo en circuitos académicos y teóricos de alta especialización. Instalada en este reducto, la mirada tiende a desconocer la vigencia de diversas formas institucionalizadas del Derecho Internacional que directa o indirectamente afectan a todo individuo y a toda colectividad en el mundo. En esta reducción del horizonte, la mirada no se percata de los continuos logros prácticos del movimiento internacional de derechos humanos durante las últimas décadas. Entre ellos está el haber impedido la continuación de las más brutales atrocidades cometidas por las dictaduras militares recientes; la organización de influyentes movimientos de reivindicación social de la mujer; la presión política para atenuar el destino catastrófico de los pueblos indígenas y de los ecosistemas naturales.

La experiencia indica que la crisis de significación social de toda disciplina institucionalizada obliga a redefinir el campo a que se aboca, su organización y su radio de investigación. Parece obvio que toda disciplina puede aspirar a un futuro en la medida en que defina de la manera más realista posible sus objetos de estudio, los métodos para acercarse a ellos, las categorías necesarias para narrar los resultados de la investigación y los condicionamientos institucionales para la propagación de conocimiento.

A mis ojos, la crisis actual de los estudios literarios tiene dos aristas principales: la primera es el hecho de que la literatura, por lo muy reducido de su consumo, hoy en día tiene poca relevancia dentro de las culturas oficiales latinoamericanas. Esto contrasta con la 
enorme "capacidad instalada" de las instituciones académicas dedicadas a su estudio. La segunda arista está en el modo con que la juventud adopta los estudios literarios como carrera profesional. Deseo dejar el término "juventud" en una vaguedad deliberada. Sin embargo, quiero relevar el sentido de esta ambigüedad con una pregunta: ¿debemos realmente hablar de los jóvenes latinoamericanos o de los que en América del Norte o en Europa emprenden estudios literarios latinoamericanistas? Esta vaguedad tiene un trasfondo del todo realista: la transnacionalización actual de la cultura.

Entro en materia recordando que la producción de literatura latinoamericana fue institucionalizada a partir del siglo XIX como parte del proyecto liberal de crear nuevas nacionalidades y modernizarlas en el proceso de integración de la economía local al mercado capitalista internacional moderno. Dentro de ese proyecto la literatura jugó el papel de lo que hoy en día llamaríamos "crítica cultural", es decir, reflexionar sobre el sentido de "la buena sociedad", "la calidad de la vida" y del "ser humano ideal" en contraste con la realidad empírica de nuestra "barbarie". Se ha dicho, además, que la literatura contribuyó al acopio de íconos para la formación de las diferentes narrativas de identidad nacional, a medida que se las creaba y distribuía en el circuito educacional. Con ello la literatura tomó el aura de sacralidad con que los Estados-nación aseguran la lealtad y la disciplina de la población. Por otra parte, el mismo proceso de consolidación de los Estadosnación convirtió a estas narrativas de identidad nacional en un espacio simbólico más para dirimir las luchas sociales.

Creo que en la actualidad todo investigador académico de la literatura latinoamericana acepta globalmente estas hipótesis aunque, en realidad, no existen estudios sociológicos que muestren empíricamente la manera en que esa iconización pueda haber tenido una influencia social. Al aceptar estas suposiciones más bien nos hemos apoyado en los constructos teóricos que periódicamente se hacen de moda en el circuito académico Benedict Anderson, por ejemplo- junto con la experiencia personal y la observación de las funciones sociales de la literatura latinoamericana en las últimas décadas.

En otras palabras, con nuestro trabajo académico hemos dado continuidad a la institución literaria liberal llevándola a una expansión gigantesca con la proliferación de programas académicos que, sin embargo, tienen fundamentos más bien fantasmagóricos, puesto que nunca han sido corroborados con el rigor de una sociología de la literatura latinoamericana. Esta todavía no existe. Fundar una sociología de la literatura latinoamericana tomará esfuerzos de varias generaciones futuras. Mientras tanto, no podemos postergar hasta ese momento nuestras reflexiones sobre nuestra profesión. De allí que estimo conveniente orientar toda reflexión sobre el estado actual de la institucionalidad literaria más bien sobre estrategias antropológicas - es decir, sobre la base de la observación personal de microexperiencias tipificables y accesibles en la cotidianeidad, agregando a esto corroboraciones surgidas de discusiones con el mayor número posible de colegas de diferentes países y continentes.

\section{UNA MICROANTROPOLOGIA DE LOS ESTUDIOS LITERARIOS}

Puesto que el origen de la institución latinoamericana de la literatura surgió de preocupaciones eminentemente sociales, se hace imperativo conocer el perfil del joven que hace estudios literarios en los países hispánicos. 
Se trata de una persona de las clases medias bajas. Luego de pasar algún tipo de examen general, al término de su educación secundaria su ingreso a los estudios humanistas aparece como la única opción realista, ya que le es imposible financiar los costos de una carrera científica o comercial de mayor prestigio. En sus años de estudios en la universidad, esta persona debe solucionar los conflictos de tener que trabajar, asistir a clases y estudiar las materias. En general, las presiones de trabajo impiden la asistencia regular a clases. "Afortunadamente", las cátedras universitarias sirven a gran número de estudiantes y la asistencia, en general, no es controlada. La inasistencia es suplida con la compra, arriendo o préstamo de notas. Por otra parte, el estudiantado debe enfrentar el alto costo del libro. Es irrealista pensar que el estudiante pueda comprar toda la bibliografia requerida; tampoco las bibliotecas universitarias disponen de fondos suficientes para ello. Esperar turno para una lectura de pocas horas en esas bibliotecas es una opción absurda por cuanto desbarata la rutina diaria. Sin embargo, la organización de los cursos no toma en cuenta estos factores. Por tanto, hay una seria dislocación entre los requisitos impuestos por los catedráticos y la práctica concreta de los estudiantes en su estudio. Como respuesta, el estudiantado organiza grupos para la compra cooperativa de textos y para leerlos o narrárselos comunitariamente. Esto es complementado con el tráfico de resúmenes o "manuales" que reemplazan la lectura de los textos canónicos. Así éstos corren el riesgo de convertirse en extraños íconos que flotan y se nombran en las discusiones estudiantiles sin la sustancia real de lecturas cuidadosas.

Luego de graduarse, la mayoría de los estudiantes de literatura busca empleo en la educación secundaria. Allí la literatura como objeto de estudio se disuelve - más bien se la utiliza como ilustración de problemas lingüísticos en la enseñanza del idioma y la lectura. En los grados más avanzados de la educación secundaria, la literatura en sí recupera una función propia, aunque muy limitada. Se la mediatiza a través de antologías que reproducen sólo trozos "representativos" de los textos canónicos. En realidad, podría decirse que las antologías son diseñadas para llamar la atención del estudiante sobre íconos culturales nacionales y "universales" - sin profundizarlos. Así se diseminan con facilidad, y casi como referentes subliminales, los valores culturales normados por los ministerios de educación.

Ya egresados de los estudios literarios universitarios, una minoría pequeñísima prosigue a los grados superiores - "maestría", "licenciatura" o doctorado. Algunos de ellos son motivados por una vocación de escritores y no esperan ningún rédito profesional de sus estudios. Una minoría aún más pequeña busca hacer carrera en la enseñanza universitaria, ya sea como profesores auxiliares, catedráticos, o investigadores. Este personal enfrenta el alto costo de los libros canonizando un número limitado de textos para ilustrar diacrónicamente sus concepciones sincrónicas de la literatura. Este canon tiende a la inflexibilidad y al estatismo, en la medida en que su renovación constante implicaría la compra de obras de autores noveles o de las últimas obras o ediciones de los autores ya consagrados. Por razones similares, ese estatismo afecta particularmente el conocimiento de la bibliografía de estudios crítico-interpretativos, nacionales y extranjeros. En última instancia este cúmulo de problemas disminuye la productividad investigativa del profesor universitario ya que es imposible que esté al día en las publicaciones recientes. Sobre este problema gravita, además, el hecho de que ningún catedrático puede vivir con un solo salario. 
A lo que apunto es que el ambiente cultural de los estudios literarios en Latinoamérica es fundamentalmente oral, en que el texto literario, teórico o interpretativo juega una función secundaria y muy especial. En la transmisión de conocimiento más bien predomina la relación de cara a cara, en el aula, en conversaciones de café, en restaurantes, jardines universitarios, casas de amigos como lugares de reunión y estudio. Los exámenes escritos no pueden ser frecuentes y no demandan la producción de trabajos de largo aliento, en que el estudiante debe demostrar la capacidad de investigar conocimiento preexistente y crear conocimiento nuevo. Esto más bien ocurre al final de la carrera, con las cortas tesis de graduación. Por lo demás, éstas pueden ser "encargadas" a investigadores profesionales que reciben buena paga por escribirlas.

Si estas observaciones son correctas, ellas sugieren un desfase en el entendimiento de nuestro objeto de estudio. Quizás la función cultural más importante del texto literario no está en sí, sino como parte del juego de creación de comunidades y generaciones de intelectuales. Es un hecho patente que, reunidos en torno a la "oralidad" de los estudios literarios, las generaciones crean el contexto para amistades, romances, camaraderías y repulsiones. Estas sensibilidades sociales marcan la forma en que las generaciones intelectuales se aproximan críticamente a los problemas nacionales e intervienen en ellos políticamente. Se podría pensar que, en realidad, nuestro objeto de estudio también debiera incluir la forma en que diferentes textos ayudan a conformar los universos simbólicos de las diferentes subjetividades organizadas que dinamizan la historia de una sociedad. En este aspecto, los estudios literarios deberían estar más cerca de la sociología de la cultura y de la antropología social.

En las últimas décadas, a este perfil institucional de los estudios literarios debe agregarse los efectos de la economía neoliberal globalizada. Los "modelos económicos y las reestructuraciones neoliberales" han hecho énfasis en la modernización acelerada de sectores competitivos de la producción nacional para insertarlos en el mercado internacional en términos de "ventaja comparativa". Esta modernización - y lo limitado de los rubros de producción con que la mayoría de los países participa en la competición internacionalha provocado altos grados de marginalización social por cuanto la economía no tiene capacidad para absorber la población laboral disponible en ningún lugar del mundo. Grandes masas de seres humanos quedan permanentemente desempleadas, subempleadas o migran constantemente en busca de trabajo. Junto con esto, para atraer inversión extranjera, en todo el mundo se busca abaratar el costo de la mano de obra reduciendo drásticamente el gasto estatal en los servicios de bienestar social.

En la medida en que el Estado ha sido el principal empleador de la intelectualidad latinoamericana dedicada a las ciencias humanas, uno de los resultados indirectos de la desinversión en servicios sociales ha sido el profundo desprestigio actual del valor de un grado universitario humanístico. En el mejor de los casos, en muchos países este tipo de educación se ha convertido en un hiato temporal para mantener fuera del mercado de trabajo, con cierta justificación digna, a sectores de la juventud. De aquí surge una gran ironía el triunfo actual del neoliberalismo económico ha destruido el significado sacro-trascendental de la institución literaria creado por el mismo liberalismo en su etapa ascendente en el siglo XIX. 
Las diferentes olas de emigrados latinoamericanos han traído a los departamentos de lenguas y literatura de América del Norte (Estados Unidos y Canadá) las consecuencias de ese neoliberalismo. Primero fueron los damnificados por alguna situación militar asociada directa o indirectamente con la Guerra Fría y la imposición del neoliberalismo - los chilenos, los uruguayos, los argentinos, los nicaragüenses, los salvadoreños, los peruanos. Últimamente, el perfil de los jóvenes inmigrados no está tan demarcado por conflictos armados. Más bien se trata de personas que han tomado conciencia de ser "los sobrantes" en su país y buscan en el extranjero algún destino personal más satisfactorio. El gran desafío que estos estudiantes deben enfrentar es el rápido desarrollo de hábitos necesarios para sobrevivir en una cultura académica fuertemente letrada, en que se asigna al texto literario y a la escritura un valor de estudio sin comparación con el que se les asigna en las mismas culturas de origen de esos textos. En cierto modo, la seriedad suprema otorgada al texto en la academia norteamericana señala un paralelo irónico con lo que ocurre en los zoológicos - a medida que avanza la destrucción de los ecosistemas naturales, en el futuro muchas especies animales solamente sobrevivirán como piezas de enorme valor en las colecciones de museos extranjeros.

Frente a los grandes problemas actuales de la cultura latinoamericana se observa una marcada diferencia entre los dos tipos recientes de inmigración académica a América del Norte. Los exiliados de las décadas de 1970 y 1980 conservaron una noción de la "sacralidad" de los estudios literarios y la volcaron en la organización de trabajos de solidaridad con sus países respectivos. Por el contrario, los inmigrados más recientes tienden a instalarse en algún sitio entre el escepticismo, el cinismo e, incluso, el nihilismo. No cuesta mucho detectar en ellos los grandes traumas de sus sociedades de origen. Se podría pensar que para ellos la problemática de la postmodernidad es una necesidad natural. Con ello la trascendencia social de los estudios literarios ha sufrido una erosión mayor.

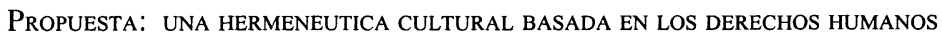

Como parte del esfuerzo geopolítico para adecuar los recursos humanos y culturales para las luchas propagandísticas y militares de la Guerra Fría, desde la década de 1960 Estados Unidos hizo enormes gastos educacionales que resultaron en una proliferación de programas doctorales de lengua y literatura. Por efecto del imperativo neoliberal de desinversión estatal en servicios sociales, actualmente las administraciones universitarias buscan desmantelar esta enorme "capacidad instalada". Por ello, como ocurre en muchas áreas universitarias, los programas graduados de los departamentos de español aseguran su supervivencia con el activo reclutamiento de estudiantes extranjeros. Aún reconociendo las tensiones que se generan entre los estudiantes hispánicos y los norteamericanos, la presencia de los estudiantes extranjeros ayuda a ilustrar concretamente problemáticas culturales que, de otro modo, el estudiante norteamericano sólo experimentaría a través de información libresca. En este contexto, el estudiante norteamericano que se especializa en literatura latinoamericana llega a caracterizarse por una mayor conciencia e interés por las problemáticas sociales y culturales de la región.

En medio de estas circunstancias - y basados fundamentalmente en el hecho de la transnacionalización de la cultura y de las grandes migraciones - propongo que, desde la 
academia norteamericana, contribuyamos a recuperar la trascendencia social de los estudios literarios latinoamericanistas mediante el uso consciente de una hermenéutica cultural basada en los derechos humanos. Esto implica la tarea de reconstruir de otro modo la continuidad práctica entre el trabajo académico y la conciencia social generada desde la década de 1960 por diversas incitaciones - el movimiento de derechos civiles; la oposición a la guerra en Vietnam; el movimiento feminista; los movimientos de solidaridad con los países latinoamericanos afectados por dictaduras y conflictos armados; el movimiento en defensa de los pueblos indígenas y de los ecosistemas naturales.

Esta proposición nace de una experiencia ya acumulada. Desde la década de 1970 en adelante se hizo cada vez más evidente la efectividad de las organizaciones internacionales no-gubernamentales de derechos humanos. Agencias como Amnistía Internacional, la Comisión Internacional de Juristas, el Consejo Mundial de Iglesias y el Comité Internacional de la Cruz Roja fueron decisivas en la limitación de las más graves violaciones de derechos humanos por parte de las dictaduras del neoliberalismo militarizado en Latinoamérica y otras partes del mundo. Además la iniciativa reciente de grupos en Estados Unidos como Pastores por la Paz, que recuerda al anterior Movimiento Santuario, confirman que la solidaridad internacional a nivel de base tiene vastas implicaciones, tanto religiosas como seculares. Recordemos, además, la movilización internacional generada por las catástrofes ecológicas y el genocidio indígena en la Amazonía, que ha dado gran visibilidad a organizaciones como Green-peace International, World Wildlife Fund, Survival International, Amigos de la Tierra Internacional, Unión Internacional para la Conservación de la Naturaleza.

En la práctica académica, la propuesta que hago implica terminar con el casi monopolio de la problemática de los derechos humanos por la abogacía para instalarla en el campo más vasto de los asuntos culturales. En mi experiencia personal, esto requiere un doble trabajo: primero, alinear una teoría de la cultura con la amplitud suficiente para dar cuenta tanto de la producción simbólica, en general, como de una acción política propia de los derechos humanos; segundo, estudiar la poética de los movimientos de derechos humanos. En cuanto al primer aspecto, he contribuido ${ }^{1}$ tomando segmentos teóricos de Max Weber, Theodor Adorno, Herbert Marcuse y Georges Bataille. Tratar el segundo aspecto involucrará a futuras generaciones de investigadores.

La producción simbólica puede ser interpretada como manifestación histórica de un desquilibrio ontológico y, por tanto, permanente e inevitable, entre las nociones de cultura y civilización. Cultura es el trabajo de autotransformación humana en la búsqueda infinita de la especie por satisfacer necesidades materiales y espirituales siempre en proceso de ser redefinidas. Cultura es la esencia histórica de la humanidad y contiene la promesa tácita la parusía - y el urgimiento hacia la liberación de toda necesidad mientras la especie exista. Esta parusía conforma la utopía del movimiento de defensa de los derechos humanos al decirse que todo ser humano tiene derecho a ser persona: es decir, por el hecho de ser humano, todo ser humano tiene el derecho prima facie de acceso total a todos los instrumentos de la cultura existentes en su sociedad.

' Hernán Vidal, Critica literaria como defensa de los derechos humanos. Series: University of California, Irvine, Hispanic Studies 2 (Newark: Juan de la Cuesta, Hispanic Monographs, 1994). 
No obstante, el potencial de esta esencia y esa utopía se manifiestan contradictoriamente en la realidad histórica - precisamente para implementar esa promesa, la humanidad debe crear sistemas burocráticos para el ahorro de plusvalía social, de excedente económico, y su inversión en la infraestructura que permite la reproducción de la sociedad. Ese ahorro de excedente lleva forzosamente a la institucionalización y administración de sistemas de alienación que reducen el consumo discriminando contra seres humanos de acuerdo con su raza, etnia, género, sexualidad, religión y convicciones políticas. Del imperativo de administrar estas alienaciones han surgido los Estados nacionales. Como tótems sagrados, ellos se levantan por sobre la sociedad civil, la cohesionan y la convocan hacia "el bien común" con la irónica dualidad de ser simultáneamente las agencias responsables de las más atroces violaciones de los derechos humanos y el único interlocutor posible para la reparación de esas violaciones.

El desequilibrio permanente entre el potencial humano de construcción de la cultura y la alienación de este en la realidad histórica de la civilización conforma una ontología trágica de la especie humana en cuanto caracteriza su manera especial de ser en el cosmos, de conocer y de expresarse. Por tanto, se desprende que una política práctica orientada a la defensa de los derechos humanos ya no puede basarse en la esperanza de explosiones revolucionarias que final y definitivamente inauguren una nueva historia para la humanidad. Como ha sido ilustrado tan claramente con la caída del bloque soviético, aún los impulsos más vastos y épicos de redención humana, impulsos que motivaron los sacrificios de tantas generaciones a través de todo el mundo, finalmente pueden ser distorsionados por las burocracias estatales. De aquí surge una ironía más en el movimiento de defensa de los derechos humanos - las leyes internacionales de derechos humanos han sido la expresión más clara del desarrollo de la modernidad y su promesa de dignificar a la especie humana con la administración científica de la sociedad. No obstante, sobre la base de ese derecho internacional debemos mirar con sospecha permanente a esos administradores. Quizás la metáfora existencial más apta para captar esta antinomia sea la de Sísifo y su tarea de empujar la roca ladera arriba diariamente, sin esperanza de descanso.

Una hermenéutica cultural basada en los derechos humanos exige que llevemos a la sala de clases la sospecha permanente de la administración burocrática de todo sistema simbólico. Esto debe darse en la manera como nos acercamos al canon literario que procesamos y administramos como burocracia académica. El canon debe ser concebido como un museo de formas simbólicas que en sí reproducen la antinomia ontológica descrita. La obra literaria intenta inútilmente crear la ilusión de un equilibrio imposible entre liberación y represión, deseo y realidad, cultura y civilización. La obra literaria debe ser considerada, entonces, como un monumento mañoso, en cuyas significaciones se debaten contradictoria y simultáneamente tendencias a la sumisión, al acomodamiento, a la negociación, a la resistencia y a la aspiración incansable a un nuevo orden de realidad.

En el estudio de la obra literaria como mónada tensionada entre el potencial humano y las alienaciones de la civilización, la función del discurso crítico es captar esas antinomias y contradicciones, desarrollar sus implicaciones y mostrar la forma en que nuestra propia vida de entes reales se debate en antinomias y contradicciones similares. En última instancia, se trata de evaluar la forma en que cada obra literaria representa el cosmos humano bien como espacio para la promoción de la vida y de la persona o bien para la violación de sus derechos. 
Es fácil entender que tal función del discurso crítico en los estudios literarios señala tareas desideologizadoras a muy largo plazo. Si es que aceptamos que las literaturas nacionales han sido uno de los elementos en la formación de las narrativas de identidad nacional, es imperativo determinar los condicionamientos simbólicos que la literatura haya podido introducir en la historia reciente de los derechos humanos en Latinoamérica. Esta revisión de la historia de las literaturas nacionales respondería a una necesidad urgente en la actualidad - la de preservar una memoria histórica de las luchas contemporáneas en defensa de los derechos humanos, apuntando constantemente al origen de sus violaciones en los mitos nacionales.

Es un hecho que en los procesos actuales de redemocratización de las sociedades latinoamericanas existe un deseo generalizado de olvidar la historia reciente. Esto involucra a todas las partes conflictivas - tanto revolucionarias como conservadoras - por motivos diferentes. Para estas últimas se trata de borrar la huella de las atrocidades cometidas por las fuerzas de seguridad del Estado; para los otros, en la derrota, se trata del prurito de exhibir a la Izquierda como cuerpo siempre doliente, siempre sufriente. Para la intelectualidad latinoamericanista rara vez se presenta una oportunidad tan especial como ésta para contribuir a corregir estas distorsiones. Ello requiere pensar en una hermenéutica cultural no solamente basada en la ley internacional de derechos humanos proclamada por las Naciones Unidas para tiempos de paz. También debemos considerar el Derecho Internacional Humanitario del Conflicto Armado, es decir las Convenciones de Ginebra y sus Protocolos Adicionales. Recordemos que la historia moderna de los derechos humanos está íntimamente relacionada con importantes conflictos armados: las revoluciones norteamericana, francesa, mexicana, soviética, y con todos los movimientos anticoloniales del siglo XX. Para crear nuevos espacios de libertad la humanidad se ha visto forzada al uso de la violencia. No obstante, el derecho internacional humanitario del conflicto armado nos señala la gran diferencia que hay entre matar a seres humanos respetando su dignidad de tales, en comparación con las regresiones animalistas que se han atestiguado en la historia más reciente.

Una hermenéutica cultural basada en la defensa de los derechos humanos indefectiblemente lleva la mirada del investigador a inquirir sobre los condicionamientos históricos, políticos, sociales y económicos que promueven el respeto por los derechos humanos o su violación. Por tanto, es preciso reconocer que, una vez adoptada esta postura hermenéutica, el investigador descubre aplicaciones cada vez más amplias, que expanden y complejizan las temáticas tradicionales de los estudios literarios. La capacidad analítica e interpretativa adquirida rebasa la noción de texto literario y la desplaza a otras formas de discursividad. Incursionar en los discursos propios de la jurisprudencia, la antropología, la sociología, la política económica, la ciencia militar, en fin, en todos los macrodiscursos culturales hoy predominantes, se hace indispensable, no sólo como apoyo de la investigación sino como material de enseñanza.

En esta expansión investigativa también debe considerarse que la acción concreta de los grupos de derechos humanos está motivada por la no-violencia activa. Por tanto, en su interpelación a los Estados nacionales en reivindicación de los derechos humanos estos grupos se ven forzados a expresarse públicamente con una alta teatralidad social que genera verdaderos rituales colectivos en medio de la cotidianeidad urbana. De allí que una 
hermenéutica cultural como la propuesta exige, a su vez, formas de investigación que hagan de la totalidad del espacio social un texto abierto a la mirada crítica, integrándose con ello formas de trabajo de campo antes privativas de las ciencias sociales. De este modo se agrega un elemento más para desahuciar la compartimentación que divide la crítica literaria de las otras ciencias humanas.

\section{IMPLICACIONES BUROCRATICO-ADMINISTRATIVAS}

Estas circunstancias refuerzan la tendencia contemporánea al desarrollo de los llamados "estudios culturales" dentro de los departamentos de idioma y literatura. En términos muy amplios, estos pueden ser definidos como el estudio de los diferentes modos en que la producción simbólica en la vida cotidiana, presente o pretérita, da sentido a la identidad y a la acción humana en la búsqueda de su reivindicación dentro de estructuras de poder hegemónico y dominante.

Ya que la sociología y la antropología latinoamericanistas no hacen de la cotidianeidad una de las prioridades de su estudio, investigar la producción simbólica generada en la cotidianeidad como espacio para la promoción de la vida humana en dignidad tiene el potencial de enriquecer extraodinariamente la oferta educacional de los departamentos de literatura. No obstante, esta riqueza a la vez profundiza tensiones burocrático-administrativas para los departamentos tradicionales de lengua y literatura que ya se venían arrastrando desde la década de 1960, con la llamada "literatura del boom". Como se recordará, la literatura asociada con el "boom", con su complejidad técnica y su desafío de la concepción liberal de la historia latinoamericana instigada por la revolución cubana, obligó a la crítica literaria académica a una total renovación conceptual y metodológica. En los departamentos de literatura ello no sólo terminó con el control peninsularista de la "corrección del idioma" sino también con el status del canon peninsular como norma ejemplar de la literariedad hispánica.

Además, el surgimiento de las dictaduras militares en Sudamérica, la revolución nicaragüense y la guerra civil en El Salvador desde la década de 1970 dieron nuevo impulso a la renovación crítica inducida por la "literatura del boom". Se amplió enormemente la experimentación teórico-metodológica para explicar el texto literario como constructo socio-histórico condicionado y también constituyente de grandes pugnas sociales. Sobre este nuevo impulso se sustentó el surgimiento de los estudios feministas y cinematográficos latinoamericanistas.

El efecto conjunto de todos estos sucesos fue el de crear un perfil culturalista de los estudios literarios latinoamericanistas que los distanció más intensamente de los peninsulares. Mientras en el peninsularismo siguió predominando una concepción del estudio literario como el entendimiento de los grandes monumentos de la cultura universal, en los estudios latinoamericanistas se hizo cada vez más énfasis en el trabajo académico como misión de compromiso social.

Debo señalar que, en mi experiencia, el distanciamiento creciente entre los estudios pensularistas y latinoamericanistas debe atribuirse a consideraciones totalmente prácticas. El hecho es que una aproximación culturalista a la problemática latinoamericana exige del estudiante no sólo un intenso entrenamiento en estrategias de lectura textual sino también 
una intensa preparación en la lógica de las ciencias sociales. En el contexto de las limitaciones temporales asociados con todo período de residencia académica, el estudiante latinoamericanista llega a considerar los requisitos peninsulares tradicionales como un obstáculo en su desarrollo intelectual. Estos requisitos ya no parecen tener una funcionalidad convincente. En mi experiencia, la introducción de la problemática de los derechos humanos intensifica esta disyuntiva, a menos que se logren puntos de contacto realmente orgánicos.

Por otra parte, una hermenéutica cultural anclada en la defensa de los derechos humanos demanda un tipo de estudiante interesado en alguna forma de misión social para su profesión. Este motivo - junto con las nuevas demandas intelectuales de una hermenéutica basada en los derechos humanos - hace cada vez más difícil atraer a ese tipo de estudiante graduado a un programa del todo literario. Como evidencia de esto puede observarse la atracción creciente que tienen para ellos los programas de literatura comparada y de historia de las mentalidades. Tales programas ofrecen al estudiante la ventaja de poder controlar los requisitos académicos de una manera más satisfactoria para sus intereses.

Es de suma importancia indicar que la necesidad de despejar las tensiones burocráticoadministrativas descritas también obedece a razones existenciales. El estudiante que adopta una hermenéutica basada en los derechos humanos debe recibir un entrenamiento especial para encarnar íntimamente sus implicaciones éticas: debe abocarse al entendimiento estético tanto de la no-violencia activa (estrategia preferida del movimiento de defensa de derechos humanos) como del derecho a la rebelión y el uso de la violencia como opción liberadora en casos extremos. Para ello necesita un espacio de reflexión y un sentimiento del trabajo intelectual y práctico del todo disociado de los indicadores usuales de progreso académico - la acumulación de créditos y cursos. Quizás la tarea más difícil para el profesor consejero académico sea el imperativo de guiar al estudiante para que llegue a formarse una visión de la cultura que de manera realista, sin perder la calma y la esperanza, se explique así mismo/a la monstruosa dualidad humana - como especie somos capaces de cometer tanto las más viles atrocidades como los actos más bellos y nobles, quizás simultáneamente.

En la marcha hacia la conclusión de estos argumentos, creo necesario relevar el hecho de que tras las problemáticas teóricas y burocrático-administrativas señaladas se encuentra otro asunto ético de difícil solución, tanto para la academia latinoamericana como para los latinoamericanistas en América del Norte. Una de las muchas consecuencias de la renovación teórica y metodológica generada por la "literatura del boom" fue el entusiasmo por fundamentar la crítica literaria como disciplina científica abocada al estudio de la "literariedad" como objeto propio y diferencial de ella. Con los años esta empresa perdió vigencia. No obstante, asentó una tendencia tecnocrática en la renovación de la disciplina. En sectores importantes de la crítica literaria académica el cambio y la renovación han obedecido a parámetros internos de la profesión, motivados especialmente por la responsabilidad de estar al día en las últimas novedades teóricas diseminadas por la industria editorial. Así es como, por ejemplo, la influencia de la estilística, del formalismo ruso, de la fenomenología y del estructuralismo cedió ante el psicoanálisis, diversas formas de semiótica y el deconstruccionismo. Muchas veces este profesionalismo va acompañado por criterios canónicos que insisten en privilegiar casi exclusivamente las grandes obras de 
autores ya consagrados y monumentalizados. Todavía es posible observar que conferencias convocadas por universidades de importancia reducen la noción de "narrativa latinoamericana contemporánea" a los autores asociados con la "literatura del boom". Colegas jóvenes que deben preparar su portafolio profesional para obtener la propiedad de su cargo ("tenure") todavía informan de directivas departamentales y decanales que exigen publicaciones circunscritas a obras y autores que han alcanzado renombre "universal". Aunque ciertamente no hay uniformidad al respecto, este también parece ser el criterio de publicación predominante en las prensas universitarias norteamericanas.

Por el contrario, una hermenéutica cultural fundamentada en la defensa de los derechos humanos no puede privilegiar solamente las grandes figuras y los grandes monumentos literarios que pocos pueden leer. Lo artístico-literario debe más bien quedar articulado a través de problemáticas que se dirijan a los modos con que diferentes formas simbólicas son usadas a nivel comunitario para la dignificación de los seres humanos y para la reivindicación de sus derechos. Esta manera diferente de problematizar la investigación muchas veces se ve obligada a concentrar la mirada sobre el trabajo cotidiano de otro tipo de intelectual el de activistas comunitarios cuya identidad quizás siempre quedará relegada al anonimato. Se trata de activistas que generan teatro, artesanía, poesía y actividades de concientización corporal y mental cuyo trabajo es de significación del todo contingente. Ese trabajo nunca será monumentalizado en la cultura oficial de su propio país y quizás tenga escasa significación para un público extranjero, excepto como problemática de derechos humanos y de solidaridad internacional.

El dilema ético a que me refiero se plantea con una pregunta que siempre agobia la conciencia moral de todo crítico literario académico, especialmente para quienes trabajamos en el extranjero - ¿quiénes son o deben ser el auditorio de nuestra producción de conocimiento?; ¿de qué manera podemos retornar a las culturas latinoamericanas de las que tomamos nuestro material de investigación y enseñanza algo del valor que nos apropiamos en términos de salario y condiciones de vida? La respuesta ideal sería producir tanto para las culturas oficiales nacionales, para los sectores marginales y para el extranjero. Sin embargo, dadas las limitaciones de nuestro tiempo, energía y recursos, esta serie de desdoblamientos de la personalidad académica es imposible. Una hermenéutica basada en la defensa de los derechos humanos por lo menos propone un criterio de balance entre estas diferentes incitaciones, señalando un espacio transnacional común a todos nosotros, de defensa de la dignidad humana más allá de diferencias nacionales, raciales, étnicas y genéricas. 
